УДК 327:330.322

08.00.00 Экономические науки

МИРОВОЙ РЫНОК ИНВЕСТИЦИЙ: ДИНАМИ-
КА, ПРОБЛЕМЫ И ТЕНДЕНЦИИ РАЗВИТИЯ

Погребная Наталья Викторовна

к.э.н., доцент кафедры институциональной

экономики и инвестиционного менеджмента

Кубанский государственный аграрныий

университет имени И.Т. Трубилина Краснодар,

Россия

РИНЦ SPIN-код: 6228-1696

nvp777@bk.ru

Дмитренко Ксения Юрьевна,

студентка экономического факультета

Кубанский государственный аграрный университет имени И.Т. Трубилина, Краснодар, Россия

Dmitrksss@gmail.com

Чекмарева Светлана Александровна

студентка экономического факультета

Кубанский государственный аграрный университет имени И.Т. Трубилина, Краснодар, Россия

sveta_001_01@mail.ru

В статье рассматриваются инвестиции - это фундаментальная часть развития экономики разных стран, как развитых, так и развивающихся. Инвестиционная деятельность определяет основу благополучного развития мировой экономики, а также способствует определению перспектив для проведения модернизации и диверсификации экономики различных стран мира. Значение иностранных инвестиций сводится к международному разделению капитала, а также к поискам более выгодных путей получения прибыли от хозяйственной деятельности за рубежом, чем в стране инвестора. Роль иностранных инвестиций сводится к развитию экономики страны, в общем, и, в частности, получателей этих инвестиций (предприятий, производств и т.д.). Стране очень выгодно получать из-за рубежа иностранные инвестиции, так как они развивают их производства, появляются новые инновационные производства, а также в национальный бюджет поступают налоги. В данной статье дается оценка мирового рынка инвестиций в 2015 году. Проведен системный анализ перспектив и тенденций развития мирового рынка инвестиций в условиях циклических колебаний мировой экономики. Рассмотрена динамика ежегодных потоков иностранных инвестиций в экономику России. Отражены последствия санкций США и Европы, введенных в 2014 году, и обозначено их влияние на инвестиционный климат России. Обозначены тенденции сокращения иностранных вложений в российскую экономику. Также выявлены основные проблемы в производственной и социальной сфере. Предложены необхо-
UDC 327:330.322

Economical sciences

\section{WORLD MARKET OF INVESTMENTS: DYNAMICS, PROBLEMS AND TENDENCIES OF DEVELOPMENT}

Pogrebnaya Natalia Victorovna

Cand.Econ.Sci., associate professor of the

Department of Institutional Economics and

Investment Management

Kuban State Agrarian University named after

I.T. Trubilin, Krasnodar, Russia

RSCI Code: 6228-1696

nvp777@bk.ru

Dmitrenko Kseniya Yurievna

students of the Economics Department

Kuban State Agrarian University named

after I.T. Trubilin, Krasnodar, Russia

Dmitrksss@gmail.com

Chekmareva Svetlana Aleksandrovna students of the Economics Department Kuban State Agrarian University named after I.T. Trubilin, Krasnodar, Russia sveta_001_01@mail.ru

In the article the investments are the fundamental part of development of the economy of different countries as developed, and developing. The investment activity defines a basis of safe development of world economy, and also promotes determination of prospects for carrying out modernization and diversification of economy of various countries of the world. The value of foreign investments comes down to the international division of the capital, and also to searches of more favorable ways of receiving profit on economic activity abroad, than in the country of the investor. The role of foreign investments comes down to development of national economy, generally, and, in particular, recipients of these investments (the enterprises, productions, etc.). It is very favorable to a country to receive from abroad foreign investments as they develop their productions, new innovative productions appear, and also taxes come to the national budget. In this article an assessment of the world market of investments in 2015 is given. The system analysis of prospects and tendencies of development of the world market of investments in the conditions of cyclic fluctuations of world economy is carried out. The dynamics of annual streams of foreign investments into economy of Russia is considered. The consequences of sanctions of the USA and Europe entered in 2014 are reflected and their influence on investment climate of Russia is designated. The tendencies of reduction of foreign investments in the Russian economy are designated. The main 
димые условия по улучшению инвестиционной привлекательности Российской Федерации

Ключевые слова: САНКЦИИ, ИНВЕСТОР, ИНВЕСТИЦИИ, КУРС ВАЛЮТ, ИНВЕСТИЦИОННЫЙ КЛИМАТ, ИНВЕСТИЦИОННАЯ ПРИВЛЕКАТЕЛЬНОСТЬ, ТЕНДЕНЦИИ, ВЛОЖЕНИЯ, ЭКОНОМИКА problems in the production and social sphere are also revealed. Necessary terms on improvement of investment appeal of the Russian Federation are offered

Keywords: SANCTIONS, INVESTOR, INVESTMENTS, EXCHANGE RATE, INVESTMENT CLIMATE, INVESTMENT APPEAL, TENDENCIES, INVESTMENTS, ECONOMY

Doi: 10.21515/1990-4665-123-105

Иностранные инвестиции - это все виды вложений имущественных (денежных) и интеллектуальных ценностей иностранными инвесторами. Иностранные инвестиции являются главным инструментом развития мировой экономики и международных экономических отношений. В настоящий момент времени потоки иностранных инвестиций значительно изменились как во всем мире, так и в России, что связано со сложившейся ситуацией на политической арене в 2014 году. России пришлось пережить не только огромное количество «западных» санкций, но и также стремительное падение рубля относительно иностранных валют. Для нашей страны этот год стал весьма значимым, при этом не только в социальном, но и экономическом плане [1].

На данный момент времени отечественная экономика находится в состоянии дисбаланса. Страна нуждается в инвестициях со стороны других государств. Иностранный капитал, который привлекается в национальную экономику, приносит положительный эффект на экономический рост, помогает внедряться в мировую экономику. Но в тоже время, использование зарубежных инвестиций ставит страну в некую зависимость, вызывает рост внешнего долга, что является негативным моментом [3].

По мнению специалистов, преобладающая доля инвестиционных потоков приходится на высокоразвитые страны, что является временным явлением. В будущем основными сферами привлечения иностранных инвестиций останутся финансово-банковский сектор, сфера услуг, прежде все- 
го информационных, электронная промышленность, биотехнология, фармацевтика, науко- и техноемкое машиностроение. В неразвитых регионах мира сохранят свою привлекательность такие отрасли, как нефте- и газодобыча, зарождающиеся секторы машиностороения, а также отдельные подотрасли аграрно-промышленного комплекса.

Что касается России на сегодняшний день вопрос об необходимости иностранных инвестиций является актуальным. На уровне правительства и глав иностранных государств обсуждается создание условий для инвестиций и обеспечение благоприятного инвестиционного климата. Российская Федерация заинтересована в иностранных инвестициях и проводит реформы по усовершенствованию инвестиционного климата в стране, что является наиболее целесообразным с усложнением геополитической ситуации на международной арене в связи с ведением санкций.

В настоящее время поток мировых инвестиций сократился, так как закончился тренд слияний и поглощений крупных корпораций, а также изза падения цен на ресурсы и высокой волатильности курсов валют. Негативно влияют на ситуацию и повышенные геополитические риски. В России экономическая ситуация не стабилизируется, следовательно, в ближайшее время страна не будет привлекательна для иностранных инвесторов. Будет наблюдаться дальнейший отток капитала и сокращение инвестиций, в таких условиях значительно снизится объем новых проектов, а действующие компании будут перекладывать нагрузку на потребителей экономить на ресурсах и заработной плате, повышать цены.

Целью данной статьи является проведение системного анализа перспектив и тенденций развития мирового рынка инвестиций в условиях циклических колебаний мировой экономики, а именно в условиях введения санкций и высокой волатильности курсов валют.

После введения санкций США и Европы в 2014 году, а также ухода с отечественного рынка крупных зарубежных компаний, начался отток ино- 
странных инвестиций из России. В 2015 году данная тенденция только усилилась, в условиях низкого курса рубля и падения цен на нефть, а также дальнейшего ухудшения международных отношений значительно сократилось количество иностранных инвесторов [7].

Санкции оказали влияние не только на российскую экономику, но и на мир в целом, изменения произошли и в мировом объёме инвестиций, что продемонстрировано на рисунке 1.

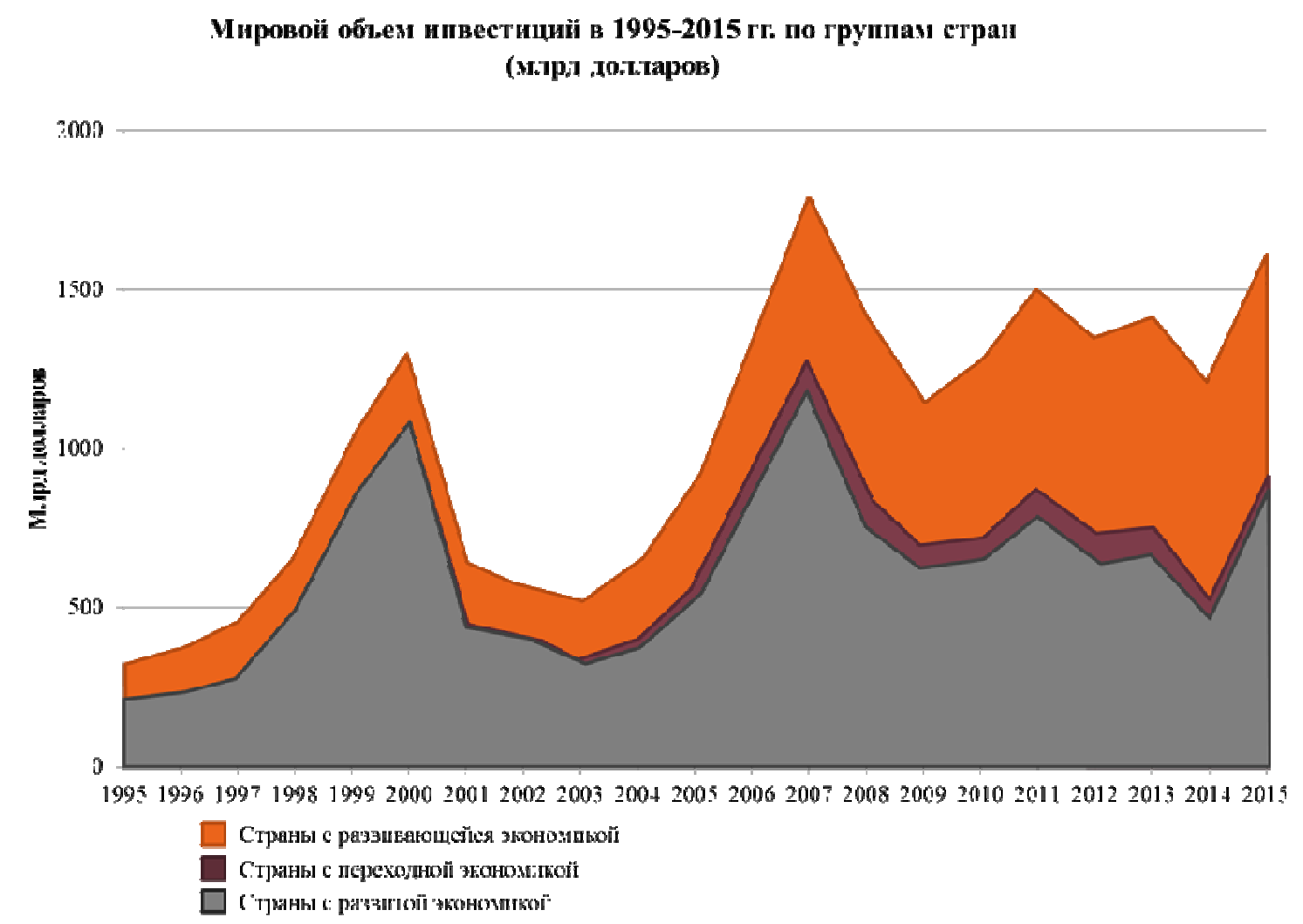

По данным ЮОІПТАД

Рисунок 1- Мировой объём инвестиций в 1995-2015гг. по группам стран, млрд дол.

Исходя из данного рисунка, можно сделать вывод о том, что в 2015 году мировой объем инвестиций увеличился на 36\% до 1,7 трлн долларов. По данным ЮНКТАД, рост инвестиционной активности был вызван скорее трансграничными слияниями и поглощениями, он подразумевал дви- 
жение финансовых ресурсов, а не производственных активов. Значительно изменилась структура иностранных инвестиций, теперь их основными получателями стали развитые страны. На данный период 55\% от общего объема мировых инвестиций приходится на развитые страны. Годовой прирост составил свыше 90\%. После низкого уровня в 2014 году, инвестиции в Европейский союз и США увеличились в 4 раза. Главную роль в этом сыграли: рост курса доллара по отношению к другим валютам на фоне снижения цен на нефть, активная внешняя политика, низкие процентные ставки, удобство ведения бизнеса, что сделало их значительно привлекательнее для инвесторов, нежели развивающиеся страны.

Далее рассмотрим топ-10 стран лидеров по притоку иностранных инвестиций за 2015 год (рис. 2).

\section{0 стран-:идеров по притоку ипострапиых ипвестиций в 2015 roду \\ (м.трл долларов)}

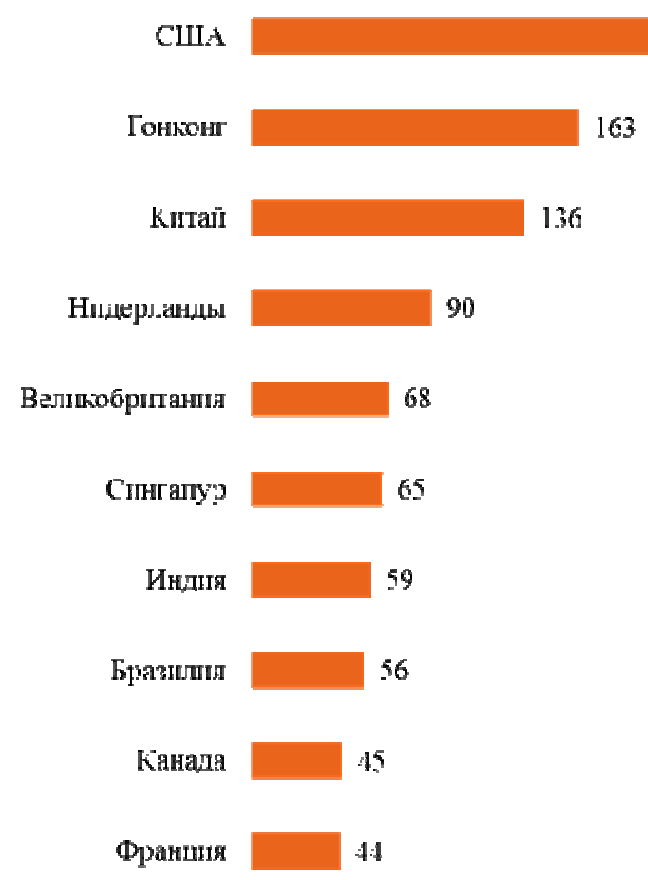

По данным ЮНКТАД

Рисунок 2 - Топ-10 стран лидеров по притоку иностранных инвестиций за 2015 год 
Анализируя рисунок, можно сказать, что объем инвестиций, которые поступили в США за год составил 384 млрд долларов, что дало им возможность выйти на первое место в мире после падения на в 2014 году. Инвестиции в Гонконг и Китай составили 163 и 136 млрд долларов соответственно. Именно для данных стран в большей степени была характерна реорганизация международных корпораций, которая связанна с перемещением финансовых средств, а также многомиллиардные сделки, заключаемые данными странами, которые практически не связанны с перемещением реальных ресурсов [2].

Объем инвестиций в страны ЕС вырос более чем на $60 \%$ и составил 426 млрд долларов. Инвестиции в Нидерланды и Великобританию увеличились на $46 \%$ и 29\%, и составили 90 и 68 млрд долларов соответственно. Наблюдается рост в экономике Франции до 44 млрд долларов, за счет погашения внутрифирменных займов и увеличения реинвестированных доходов.

На развивающиеся страны Азии приходится более трети от мирового объема инвестиций, прирост составил $15 \%$ до 548 млрд долларов. Позитивные тенденции наблюдаются также и в Индии, приток инвестиций увеличился почти в два раза до 59 млрд долларов за счет благоразумных мер правительства страны по улучшению инвестиционного климата [6].

Однако многие государства утратили инвестиционную привлекательность, в следствии падения цен на нефть и другие ресурсы. Так, приток иностранных инвестиций в страны Африки снизился на $31 \%$ до 38 млрд долларов. Сокращение инвестиций в Нигерию составило 27\%,в ЮАР - 74\%, а в Латинскую Америку - 19\%, что показано на рисунке 3 [6].

В странах с переходной экономикой, в том числе и в России, по данным ЮНКТАД зафиксировано снижение поступления иностранных инвестиций более чем в 2 раза, что связано с осложнением геополитической ситуации и снижением уровня доверия инвесторов. По оценкам ЮНКТАД 
общий объем поступивших иностранных инвестиций в Россию составил около 1,7 млрд долларов против 20,95 млрд в 2013 году. Зарубежные компании перестали вкладывать свои капиталы в машиностроение, в высокотехнологичное производство, многие автомобильные заводы, действовавшие на территории РФ, вынуждены были свернуть свою деятельность. Сложности наблюдаются также в сфере здравоохранения, в фармацевтической промышленности. Стоимость зарубежных препаратов существенно выросла, а отечественная фармацевтическая промышленность слишком слабо развита, чтобы восполнить дефицит и ценовую недоступность зарубежных аналогов. Политически обусловленные решения о введении санкций сказались на товарообороте, многие продукты и товары, до того относительно свободно попадавшие на российский рынок, отныне не доступны. Либо их цена кусает не только малоимущих покупателей, но и тех, которые относятся к так называемому среднему классу [3].

Прирост потоков нцостраншых инвестиций по регионам в 2015/2014 гт. (м.трд до.тларов)
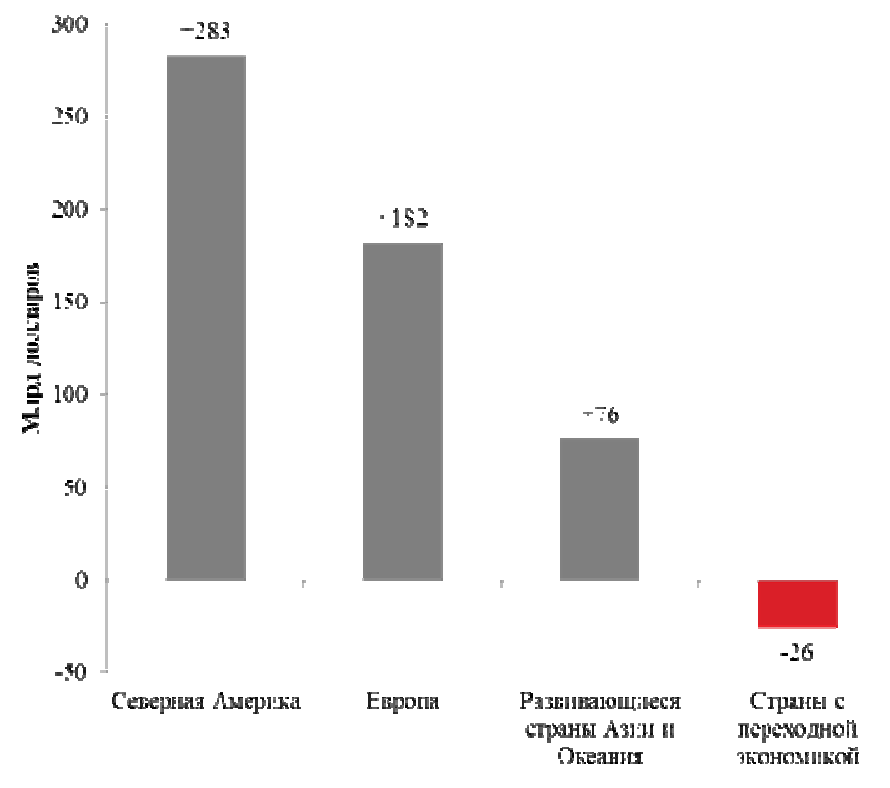

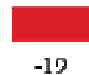

(1)

Avepuza II
Kaphбекulf ติaccĕ๋́

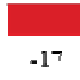

Atruka

По данным ЮНКТАД

Рисунок 3 - Прирост потоков иностранных инвестиций по регионам за 2014 - 2015 гг., млрд дол. 
О снижении активности иностранных инвесторов свидетельствуют и данные рейтинга привлекательности стран BDO International Business Compass, разрабатывающимся институтом мировой экономики в Гамбурге. В 2015 году среди 174 стран Россия занимает сотую строчку рейтинга, что ниже Вьетнама, Никарагуа, Парагвая и других развивающихся стран (таблица 1).

Таблица 1 - РейтингBDO International Business Compass, 2015 г.

\begin{tabular}{|c|c|c|}
\hline № & Страна & Рейтинговое значение/Индекс \\
\hline 1 & Швейцария & 81,88 \\
\hline 2 & Сингапур & 81,03 \\
\hline 3 & Гонконг & 80,17 \\
\hline 4 & Норвегия & 79,04 \\
\hline 5 & Дания & 79,04 \\
\hline 6 & Нидерланды & 77,71 \\
\hline 7 & Канада & 76,98 \\
\hline 8 & Великобритания & 75,58 \\
\hline 9 & Швеция & 75,72 \\
\hline 10 & Новая Зеландия & 49,11 \\
\hline \multicolumn{2}{|c|}{..} \\
\hline
\end{tabular}

Данную ситуацию обусловили политические условия и усиление административных барьеров для ведения бизнеса, что вызвано санкциями, а также ростом административной нагрузки.

Сокращение поступлений иностранных инвестиций в Россию подтверждает Центральный Банк РФ [5], данная ситуация отражена на рисунке 4. 
Прммые инвестиции в Россию и -за рубежа в 2010-II квартале 2015 п. сальдо операший

(млн цолјнаров)

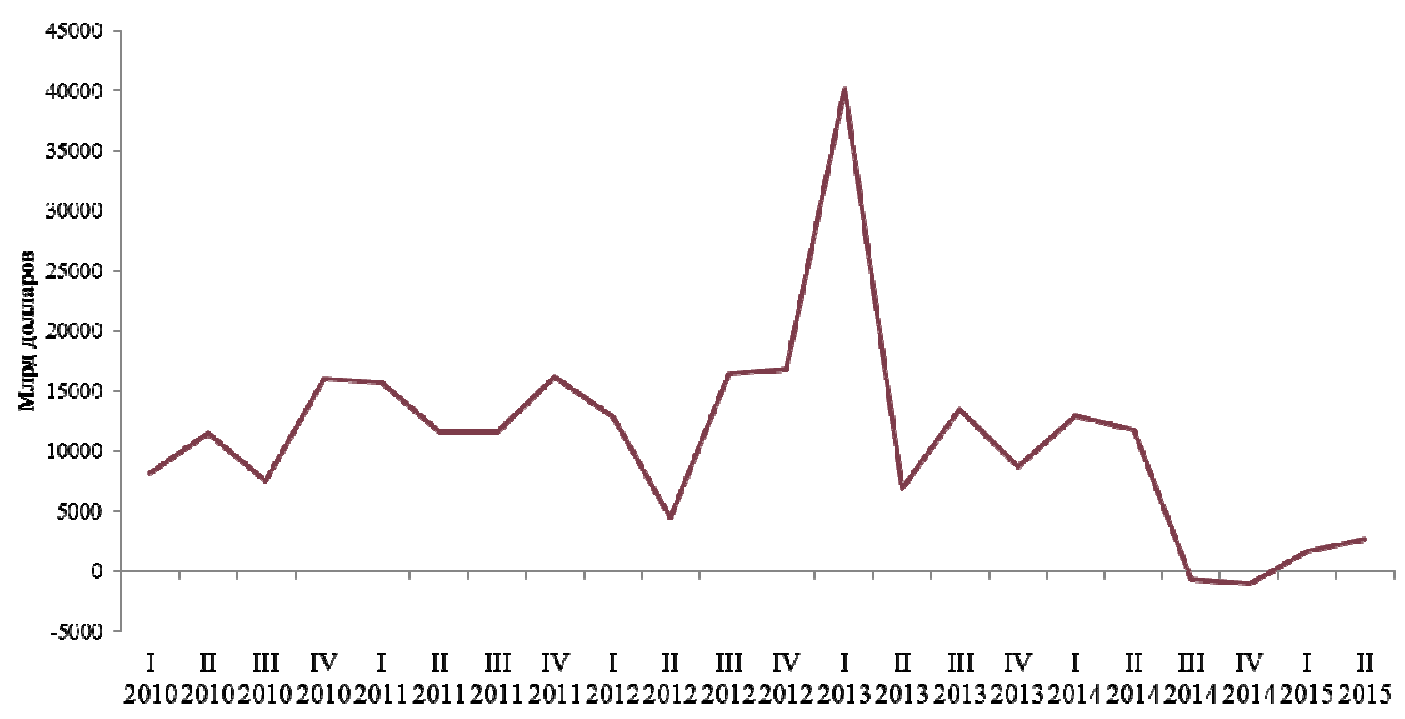

По датпттм ТТеттробантка РФ

Рисунок 4 - Прямые инвестиции в Россию из-за рубежа в 20102015гг., млн дол.

В Россию из зарубежных стран поступление иностранных инвестиций составило за первое полугодие около 4,34 млрд долларов. Резкое падение началось после обвала курса рубля ещё в III и IV кварталах 2014 года, именно тогда за долгие годы сальдо операций по инвестициям впервые стало отрицательным [5].

Можно сделать вывод о том, что сократилось количество новых инвесторов в России, а старые стремятся покинуть российский рынок. В конце года многие из них начали особенно активно избавляться от акций российских компаний, иностранные инвесторы считают ведение бизнеса в России бесперспективным. В 2015 году закрылись многие компании от небольших организаций до крупных мировых корпораций, проблемы появились во многих сферах, остановились производственные циклы на ряде предприятий промышленности, ощущается нехватка материалов и ком- 
плектующих поставлявшихся ранее из-за границы[3]. Примером может послужить закрытие производства автомобилей Opel и GeneralMotors [4].

В IT сфере закрылись офисы AdobeSystems, Google, Skype, в банковской сфере сократил своё присутствие Raiffeisen Bank. B нефтяном секторе из проектов на территории РФ вышла американская компания ConocoPhillips.

Оставшись практически без поддержки отечественные предприниматели предпочитают финансировать в другие государства, а иностранные инвесторы тем временем покидают российский рынок. За первое полугодие, по данным Центрального Банка РФ, объем инвестиций за рубеж превысил в 2 раза, чем в Россию, и составил 10,2 млрд долларов [3].

Резюмируя, стоит отметить, что для привлечения иностранных инвестиций в первую очередь должны быть созданы комфортные условия для инвестирования. Низкая квалификация работников инедостаточная финансовая грамотность населения,износ производственных мощностей в целом отталкивают иностранных инвесторов. По нашему мнению для улучшения инвестиционной привлекательности для иностранных инвесторов необходимо создать следующие условия:

1.Установить наиболее значимые направления для иностранных инвестиций, затем обеспечить поддержку государства по этим направлениям;

2. Сделать доступнее фондовый рынок методом своевременного изменения законодательства, также позволить инвесторам страховать свои риски по аналогии с европейскими фондовыми биржами;

3. Предоставить инвесторам льготы по налогообложению на прибыль;

4. Обновить производственные мощности;

5. Обеспечить работникам возможность повышения квалификации;

6. Поддерживать развитие конкуренции. 


\section{ЛИТЕРАТУРА}

1.Броварец А. К., Погребная Н. В. Национальная платежная система России: прогнозы и перспективы. В сборнике: Проблемы развития современной экономики в условиях глобальных вызовов и трансформации экономического пространства. Материалы международной научно-практической конференции студентов, аспирантов и молодых ученых. 2015. С. 198-200.

2. Зубченко А.А. Иностранные инвестиции: учеб. пос. - М.: Книгодел, 2014. - 160 c.

3. Кулич М. В., Погребная Н. В. Политика импортозамещения в отечественной экономике: плюсы и минусы санкций. Материалы международной научнопрактической конференции «Современные тенденции развития экономики и управления: проблемы и решения». Издательство: Краснодарский центр научно-технической информации (Краснодар). 2016. - С. 47-52.

4. Ример М.И. Экономическая оценка инвестиций: Учебник для вузов. - 3-е изд., переработанное и дополненное. - СПб.: Питер, 2014 г. - 416 с.

5. Банк России: Инфляция в I квартале 2015 года может превысить 10\% [Электронный ресурс Режим доступа: URL: http://www.rosbalt.ru/business/2014/12/11/1347526.html

6. Куда уходят институциональные инвесторы с российского рынка? [Электронный ресурс] Режим доступа: URL: http://www.moluch.ru/archive/76/12890/

7. Санкции 2014: уменьшатся ли инвестиционные потоки между Россией и лидерами Европейского союза - Францией и Германией [Электронный ресурс] Режим доступа: URL:http://www.moluch.ru/archive/76/12890/

\section{REFERENCES}

1.Brovarec A. K., Pogrebnaja N. V. Nacional'naja platezhnaja sistema Rossii: prognozy i perspektivy. V sbornike: Problemy razvitija sovremennoj jekonomiki v uslovijah global'nyh vyzovov i transformacii jekonomicheskogo prostranstva. Materialy mezh-dunarodnoj nauchno-prakticheskoj konferencii studentov, aspirantov i molodyh uche-nyh. 2015. S. 198-200.

2. Zubchenko A.A. Inostrannye investicii: ucheb. pos. - M.: Knigodel, 2014. - 160 s.

3. Kulich M. V., Pogrebnaja N. V. Politika importozameshhenija v otechestvennoj jekono-mike: pljusy i minusy sankcij. Materialy mezhdunarodnoj nauchno-prakticheskoj konferencii «Sovremennye tendencii razvitija jekonomiki i upravlenija: problemy i reshenija». Izdatel'stvo: Krasnodarskij centr nauchno-tehnicheskoj informacii (Krasnodar). 2016. - S. 4752.

4. Rimer M.I. Jekonomicheskaja ocenka investicij: Uchebnik dlja vuzov. - 3-e izd., pere-rabotannoe i dopolnennoe. - SPb.: Piter, 2014 g. - 416 s.

5. Bank Rossii: Infljacija v I kvartale 2015 goda mozhet prevysit' 10\% [Jelektronnyj resurs] Rezhim dostupa: URL: http://www.rosbalt.ru/business/2014/12/11/1347526.html

6. Kuda uhodjat institucional'nye investory s rossijskogo rynka? [Jelektronnyj resurs] Rezhim dostupa: URL: http://www.moluch.ru/archive/76/12890/

7. Sankcii 2014: umen'shatsja li investicionnye potoki mezhdu Rossiej i liderami Evropejskogo sojuza - Franciej i Germaniej [Jelektronnyj resurs] Rezhim dostupa: URL:http://www.moluch.ru/archive/76/12890/ 